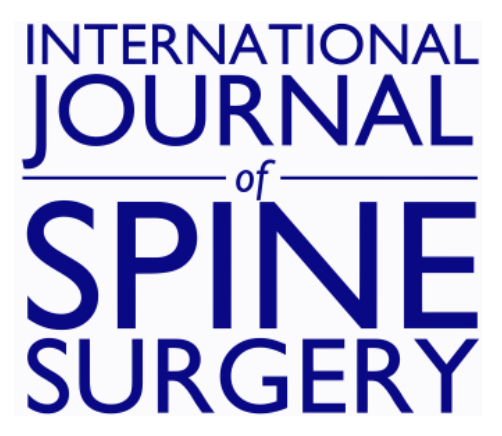

\title{
Do Patients with Back Pain-Dominant Symptoms Improve After Lumbar Surgery for Radiculopathy or Claudication?
}

Srikanth N. Divi, Barrett I. Woods, Dhruv K.C. Goyal, Matthew S. Galetta, Kristen J. Nicholson, Andrew L. Dimatteo, Meghan E. Lam, Mahir A. Qureshi, D. Greg Anderson, Mark F. Kurd, Jeffrey A. Rihn, Ian D. Kaye, Christopher K. Kepler, Alan S. Hilibrand, Alexander R. Vaccaro, Kristen E. Radcliff and Gregory D. Schroeder

Int J Spine Surg 2021, 15 (4) 780-787

doi: https://doi.org/10.14444/8100

http://ijssurgery.com/content/15/4/780

This information is current as of April 26, 2023.

Email Alerts Receive free email-alerts when new articles cite this article. Sign up at: http://ijssurgery.com/alerts 


\title{
Do Patients with Back Pain-Dominant Symptoms Improve After Lumbar Surgery for Radiculopathy or Claudication?
}

\author{
SRIKANTH N. DIVI, MD, BARRETT I. WOODS, MD, DHRUV K.C. GOYAL, MD, MATTHEW S. GALETTA, \\ BA, KRISTEN J. NICHOLSON, PHD, ANDREW L. DIMATTEO, MS, MEGHAN E. LAM, BA, MAHIR A. \\ QURESHI, BS, D. GREG ANDERSON, MD, MARK F. KURD, MD, JEFFREY A. RIHN, MD, IAN D. KAYE, \\ MD, CHRISTOPHER K. KEPLER, MD, MBA, ALAN S. HILIBRAND, MD, ALEXANDER R. VACCARO, \\ MD, PHD, MBA, KRISTEN E. RADCLIFF, MD, GREGORY D. SCHROEDER, MD \\ Department of Orthopaedic Surgery, Rothman Institute, Thomas Jefferson University, Philadelphia, Pennsylvania
}

\begin{abstract}
Background: Currently, few studies have examined whether patients with back or leg pain-predominant symptoms fare better clinically after lumbar spine surgery; therefore, the purpose of this study was to determine whether patients with back pain-dominant symptoms improved to a similar degree as patients with mixed or leg pain-dominant symptoms after lumbar surgery.

Methods: A retrospective cohort study was conducted at a single academic center, in which patients were stratified into three groups: (1) back pain-dominant group (B) (visual analog score [VAS] back - VAS leg $\geq 1.0$ point), (2) neutral group (N) (VAS back - VAS leg $<1.0$ point), or (3) leg pain-dominant group (L) (VAS leg - VAS back $\geq 1.0$ point), using a VAS threshold difference of 1.0 point. As a secondary analysis, the VAS leg-to-back pain (LBR) ratio was used to further stratify patients: (1) nonleg pain-dominant (NLPD) group (LBR $\leq 1.0)$ or (2) leg pain-dominant (LPD) group (LBR > 1.0). Patient outcomes, including physical component score of the short form-12 survey (PCS-12), mental component score of the short form-12 survey (MCS-12), and Oswestry Disability Index (ODI), were identified and compared between groups using univariate and multivariate analysis.

Results: There were no significant differences in preoperative, postoperative, or delta scores for PCS-12 or ODI scores between groups. In patients undergoing decompression surgery, those with back pain-dominant or mixed symptoms (B, N, or NLPD groups) did not improve with respect to MCS-12 scores after surgery $(P>.05)$, and those with leg pain-dominant symptoms (LPD group) had greater delta MCS-12 scores $(P=.046)$ and greater recovery rates $(P=.035)$. Multiple linear regression did not find LPD to be an independent predictor of PCS-12 or ODI scores.

Conclusion: Patients undergoing lumbar decompression surgery and leg pain-dominant symptoms noted a greater improvement in MCS-12 scores; however, there were no differences in PCS-12 or ODI scores.

Level of Evidence: 3.

Clinical Relevance: Patients undergoing lumbar decompression surgery demonstrate no major clinically significant differences when split up by pain-dominance groups.

\section{Lumbar Spine}

Keywords: patient-reported outcome measurements (PROMs), physical component score of the short form-12 (PCS12), mental component score of the short form-12 (MCS-12), Oswestry Disability Index (ODI), visual analog scale back pain (VAS back), visual analog scale leg pain (VAS leg), VAS pain dominance, lumbar surgery
\end{abstract}

\section{INTRODUCTION}

The prevalence of symptomatic lumbar disease increases with age and is related to structural changes in the intervertebral disc, facet joints, as well as supporting ligaments, which cause a combination of low back pain (LBP) and neurologic compression. ${ }^{1}$ LBP is estimated to affect nearly $40 \%$ of the global population and is one of the most common reasons for occupational disability., ${ }^{2,3}$ It incurs a large societal burden, both in terms of lost productivity as well as increased healthcare costs.
While the majority of acute-onset back pain is benign and resolves with nonoperative treatment, a small proportion of patients continue to have significant disability. ${ }^{4,5}$ Increases in costs have not been met by a concomitant improvement in pain and functionality for patients with LBP, and surgical management of back pain is controversial. ${ }^{6}$ On the contrary, lumbar spine surgery is effective in the treatment of radiculopathy or neurogenic claudication, especially in those who fail nonoperative management. ${ }^{7}$ Due to this discrepancy, most 
surgeons perform lumbar spine surgery for neurologic symptoms exclusively. However, patients with lumbar degenerative disease, such as degenerative spondylolisthesis or lumbar spinal stenosis, typically present with a combination of both LBP and leg pain, and these patients may experience varying degrees of back or leg pain predominance despite the same underlying diagnosis. To date, only few studies have examined whether patients with back or leg pain-predominant symptoms fare better clinically. ${ }^{1,8-12}$

Long-term results from the Maine Lumbar Spine Study and the Spine Patient Outcome Research Trial assessing improvement in leg or back paindominant patients showed that patients with leg pain-dominant symptoms improved significantly more than those in the back pain-dominant groups. ${ }^{8,12}$ However, multiple other risk factors have been identified for improvement in patient outcomes after lumbar surgery, such as age, smoking status, sex, and body mass index. ${ }^{13-15}$ Previous studies have had limited ability to differentiate the importance of back or leg pain dominance in the presence of other confounders. The aim of the present study is to determine whether patients with predominantly back pain symptoms would benefit from lumbar spine surgery to a similar extent as those with leg pain only or mixed symptoms.

\section{METHODS}

\section{Patient Selection}

After Institutional Review Board approval, nonconsecutive patients over the age of 18 years that received surgical intervention to address lumbar degenerative disease between January 1, 2013, and December 31, 2017, were retrospectively identified. Patients who underwent between one and five levels of lumbar decompression with or without fusion were included in the cohort. Only patients undergoing elective surgery for a diagnosis of degenerative spondylolisthesis, degenerative scoliosis, lumbar spinal stenosis, or recurrent disc herniation were included in the dataset. Patients with less than 12 months of clinical follow-up or those who underwent surgical intervention to address malignancy, infection, trauma, or revision surgery were excluded. This study was approved by the Institutional Review Board at the Thomas Jefferson University Hospital. Each author certifies that his or her institution approved the human protocol for this investigation and that all investigations were conducted in conformity with ethical principles of research.

\section{Study Design and Patient Outcomes}

Demographic and surgical characteristics were collected and recorded from the electronic medical record, including age, sex, body mass index $\left(\mathrm{kg} / \mathrm{m}^{2}\right)$, smoking status (never, current, former smoker), months of clinical follow-up, duration of symptoms ( $<3$ months, 3 to 6 months, $>6$ months), whether or not the patient was receiving workers compensation benefits preoperatively, number of levels decompressed ( 1 to 5 levels), and number of levels fused (0 to 4 levels). The following preoperative and postoperative patient-reported outcome measurements were queried and recorded: the physical component score and mental component score of the short form-12 health survey (PCS-12 and MCS12, respectively), the Oswestry Disability Index (ODI), and the visual analog scale back (VAS back) and leg (VAS leg) pain scales. Patients undergoing decompression only or combined decompression and fusion were analyzed separately. Patients were stratified into subgroups based on two different methods. For the primary analysis, patients were split into one of three groups based on pain predominance. A 1.0-point threshold difference between preoperative VAS back and leg pain was used to determine each group: (1) back (B)dominant group (VAS back - VAS leg $\geq 1.0$ point); (2) neutral (N) group $(-1.0<$ VAS back - VAS leg $<1.0$ points); or (3) leg (L)-dominant group (VAS leg - VAS back $\geq 1.0$ points). A secondary analysis was used to substratify the cohort using a different criterion, using the VAS leg-to-back pain ratios: (1) nonleg pain-dominant (NLPD) group (leg-to-back pain ratio $\leq 1.0$ ) or (2) leg pain-dominant (LPD) group (leg-to-back pain ratio $>1.0$ ). Both of these analytic methods have been previously applied in the cervical spine, but not in the lumbar spine. ${ }^{16,17}$

\section{Statistical Analysis}

Before performing within- and between-group comparisons, the data were tested for normality of distribution using measures of skewness and kurtosis and the Shapiro-Wilk test. Categorical variables between groups were compared using Pearson's chisquared test or Fisher's exact test. Continuous variables between groups were compared using an independent samples $t$ test or one-way analysis of 
Table 1. Demographic data and surgical characteristics between visual analog scale pain groups.

\begin{tabular}{|c|c|c|c|c|}
\hline & Back (B) $(n=115)$ & Neutral $(\mathrm{N})(n=236)$ & $\operatorname{Leg}(L)(n=143)$ & ${\text { Univariate Analysis }(P \text { Value })^{a}}^{a}$ \\
\hline \multicolumn{5}{|l|}{ Demographic data } \\
\hline Age $(95 \% \mathrm{CI})$ & $58.4(55.7,61.1)$ & $62.0(60.5,63.6)$ & $62.6(60.9,64.4)$ & $.013^{\mathrm{b}}$ \\
\hline Sex, $n(\%)$ & & & & .785 \\
\hline $\mathrm{M}$ & $72(62.6)$ & $141(59.7)$ & $90(62.9)$ & \\
\hline $\mathrm{F}$ & $43(37.4)$ & $95(40.3)$ & $53(37.1)$ & \\
\hline BMI & $29.9(28.8,31.1)$ & $30.7(29.8,31.5)$ & $29.7(28.8,30.6)$ & .267 \\
\hline \multicolumn{4}{|l|}{ Smoking status, $n(\%)$} & .624 \\
\hline Never & $82(71.3)$ & $154(65.3)$ & $90(62.9)$ & \\
\hline Current & $7(6.1)$ & $22(9.3)$ & $12(8.4)$ & \\
\hline Former & $26(22.6)$ & $60(25.4)$ & $41(28.7)$ & \\
\hline Follow-up (months) & $13.2(12.7,13.7)$ & $13.6(13.0,14.2)$ & $13.2(12.7,13.8)$ & .547 \\
\hline \multicolumn{4}{|c|}{ Duration of symptoms, $n(\%)$} & .623 \\
\hline$<3$ months & $72(62.6)$ & $132(55.9)$ & $77(53.8)$ & \\
\hline 3 to 6 months & $30(26.1)$ & $68(28.8)$ & $46(32.2)$ & \\
\hline$>6$ months & $13(11.3)$ & $36(15.3)$ & $20(14.0)$ & \\
\hline \multicolumn{4}{|c|}{ WC received before surgery? $n(\%)$} & .132 \\
\hline No & $108(93.9)$ & $225(95.3)$ & $141(98.6)$ & \\
\hline \multirow{2}{*}{\multicolumn{5}{|c|}{ Surgical characteristics, $n(\%)$}} \\
\hline & & & & \\
\hline \multicolumn{4}{|c|}{ Levels decompressed } & .078 \\
\hline 1 & $63(54.8)$ & $104(44.1)$ & $62(43.4)$ & \\
\hline 2 & $39(33.9)$ & $76(32.2)$ & $50(35.0)$ & \\
\hline 3 & $10(8.7)$ & $52(22.0)$ & $27(18.9)$ & \\
\hline 4 & $2(1.7)$ & $4(1.7)$ & $4(2.7)$ & \\
\hline 5 & $1(0.9)$ & $0(0.0)$ & $0(0.0)$ & \\
\hline \multicolumn{4}{|l|}{ Levels fused } & .318 \\
\hline 0 & $34(29.6)$ & $90(38.1)$ & $52(36.4)$ & \\
\hline 1 & $53(46.1)$ & $112(47.5)$ & $62(43.5)$ & \\
\hline 2 & $21(18.3)$ & 28 (11.9) & $23(16.1)$ & \\
\hline 3 & $7(6.0)$ & $6(2.5)$ & $6(4.0)$ & \\
\hline
\end{tabular}

Abbreviations: BMI, body mass index; F, female; M, male; WC, workers compensation.

${ }^{\mathrm{a}}$ One-way analysis of variance, Pearson chi-square analysis, or the Fisher exact test used to compare baseline demographics and surgical characteristics between groups. ${ }^{\mathrm{b}}$ Indicates significance $(P<.05)$.

variance testing with Bonferroni post hoc analysis. Within-group comparisons were conducted using paired samples $t$ testing to assess change from baseline to postoperative measurements. Two other surrogate measures for improvement postoperatively were calculated: a recovery ratio (RR) and the percentage of patients achieving minimal clinically important difference (MCID). RR was calculated using the following equation: (delta score/["optimal" score - baseline score]), where 100 and 0 were used as "optimal" scores for PCS-12/MCS-12 and ODI/VAS back/VAS leg, respectively, and the percent MCID was calculated for each group using the following threshold values for improvement: PCS-12, 8.8 points; MCS-12, 9.3 points; and ODI, 6.8 points. ${ }^{18-20}$ Finally, a series of multiple linear regressions was performed to determine whether having neutral pain or leg pain-predominant symptoms predicted improvement compared with the back pain-predominant group, adjusting for demographic and surgical variables. All statistical comparisons were conducted using the Statistical Package for the Social Sciences (IBM Corporation, Armonk, NY) version 24. Statistical significance was defined as $P<.05$.

\section{RESULTS}

Overall, 494 patients were included, with 115 $(23.3 \%)$ in the B group, $236(47.8 \%)$ in the $\mathrm{N}$ group, and the remaining $143(28.9 \%)$ in the $\mathrm{L}$ group (Table 1$)$. A total of $303(61.3 \%)$ patients were male, average age was $61.4(60.3,62.5)$ years, and mean body mass index was $30.2(29.7,30.8) \mathrm{kg} / \mathrm{m}^{2}$. Patients in the B group were significantly younger than patients in the $\mathrm{N}$ and $\mathrm{L}$ groups (58.4 years versus 62.0 years and 62.6 years, respectively; $P=$ $.013)$. There was a total of $326(66.0 \%)$ individuals who identified as never smokers, $41(8.3 \%)$ identified as current smokers, and the remaining 127 $(25.7 \%)$ identified as former smokers. Average length of clinical follow-up was 13.4 (13.1, 13.8) months, and there were $281(56.9 \%)$ patients who demonstrated symptoms for $<3$ months, 144 $(29.1 \%)$ for 3 to 6 months, and $69(14.0 \%)$ for $>6$ months before receiving surgical intervention. Out of the entire cohort, $20(4.0 \%)$ patients were receiving workers compensation benefits before surgery. Finally, a total of 176 patients underwent decompression only, with most cases involving either one (224 patients, $46.4 \%$ ) or two (165 
Divi et al.

Table 2. Patient-reported outcome measurements between visual analog score pain groups. ${ }^{a}$

\begin{tabular}{|c|c|c|c|c|}
\hline & Back (B) & Neutral (N) & Leg (L) & Univariate Analysis ( $P$ Value) \\
\hline \multicolumn{5}{|l|}{ PCS-12 } \\
\hline Delta $(95 \%$ CI $)$ & $11.0(7.5,14.5)$ & $9.9(7.6,12.2)$ & $9.9(6.6,13.3)$ & .854 \\
\hline RR, \% & 15.0 & 13.7 & 13.7 & .911 \\
\hline$\%$ MCID & 55.9 & 47.8 & 53.8 & .816 \\
\hline \multicolumn{5}{|l|}{ MCS-12 } \\
\hline Delta & $1.6(-2.0,5.1)$ & $1.1(-1.6,3.6)$ & $4.4(1.4,7.4)$ & .205 \\
\hline $\mathrm{RR}, \%$ & 2.0 & 4.2 & 5.7 & .219 \\
\hline \multirow{2}{*}{\multicolumn{5}{|c|}{ ODI }} \\
\hline & & & & \\
\hline Delta & $-21.6(-28.7,-14.5)$ & $-24.1(-29.3,-18.9)$ & $-18.1(-25.6,-10.5)$ & 679 \\
\hline$R R, \%$ & 46.4 & 51.5 & 4.6 & .636 \\
\hline$\%$ MCID & 70.6 & 71.1 & 67.3 & .885 \\
\hline \multicolumn{5}{|l|}{ VAS back } \\
\hline Delta & $-4.6(-7.5,-1.8)$ & $-3.3(-4.1,-2.5)$ & $-1.2(-2.1,-0.3)$ & $.002^{\mathrm{b}}$ \\
\hline $\mathrm{RR}, \%$ & 43.9 & 40.7 & 21.6 & .376 \\
\hline$\%$ MCID & 67.6 & 62.2 & 36.5 & $.004^{\mathrm{b}}$ \\
\hline \multicolumn{5}{|l|}{ VAS leg } \\
\hline Delta & $-1.6(-3.0,-0.2)$ & $-3.9(-4.6,-3.1)$ & $-4.9(-5.8,-3.9)$ & $.001^{\mathrm{b}}$ \\
\hline $\mathrm{RR}, \%$ & 19.4 & 45.5 & 64.6 & .117 \\
\hline$\%$ MCID & 50.0 & 63.3 & 73.1 & .094 \\
\hline \multirow{2}{*}{\multicolumn{5}{|c|}{ PCS-12 }} \\
\hline & & & & \\
\hline Delta & $11.1(8.5,13.7)$ & $8.3(6.6,9.9)$ & $10.6(8.1,13.0)$ & .119 \\
\hline $\mathrm{RR}, \%$ & 15.0 & 11.3 & 14.8 & .133 \\
\hline$\%$ MCID & 59.3 & 43.8 & 52.7 & .081 \\
\hline \multicolumn{5}{|l|}{ MCS-12 } \\
\hline Delta & $3.6(1.4,5.8)$ & $4.3(2.5,6.1)$ & $2.8(0.3,5.3)$ & .593 \\
\hline $\mathrm{RR}, \%$ & 5.1 & 6.1 & 2.2 & .376 \\
\hline$\%$ MCID & 27.2 & 30.1 & 23.1 & .421 \\
\hline \multicolumn{5}{|l|}{ ODI } \\
\hline Delta & $-21.1(-25.5,-15.9)$ & $-20.2(-23.4,-16.4)$ & $-21.0(-25.5,-16.7)$ & .908 \\
\hline $\mathrm{RR}, \%$ & 26.4 & 42.9 & 38.8 & .557 \\
\hline$\%$ MCID & 75.3 & 69.9 & 72.5 & .749 \\
\hline \multicolumn{5}{|l|}{ VAS back } \\
\hline Delta & $-3.9(-4.6,-3.3)$ & $-3.6(-4.1,-3.1)$ & $-1.7(-2.4,-1.2)$ & $<.001^{\mathrm{b}}$ \\
\hline $\mathrm{RR}, \%$ & 50.9 & 44.7 & 25.7 & .108 \\
\hline$\%$ MCID & 67.9 & 63.7 & 44.0 & $.004^{\mathrm{b}}$ \\
\hline \multicolumn{5}{|l|}{ VAS leg } \\
\hline Delta & $-1.7(-2.4,-1.0)$ & $-3.8(-4.4,-3.2)$ & $-5.5(-6.2,-4.9)$ & $<.001^{\mathrm{b}}$ \\
\hline $\mathrm{RR}, \%$ & 38.0 & 51.6 & 72.2 & $<.001^{\mathrm{b}}$ \\
\hline$\%$ MCID & 38.3 & 62.3 & 78.0 & $<.001^{\mathrm{b}}$ \\
\hline
\end{tabular}

Abbreviations: MCID, minimum clinically important difference; MCS-12, mental component score of the short form-12 survey; ODI, Oswestry Disability Index; PCS-12, physical component score of the short form-12 survey; RR, recovery ratio; VAS, visual analog score.

${ }^{a}$ Back, neutral, and leg pain-dominant groups outcomes compared with univariate analysis (paired samples $t$ test, one-way analysis of variance with Bonferroni post hoc analysis, or Pearson chi-square analysis) and multivariate regression. Recovery ratios were defined as (delta outcome score/[optimal outcome score - observed outcome score]), where the following optimal outcome scores were used: 100 (PCS-12 and MCS-12) or 0 Neck Disability Index. The percentage of patients reaching the MCID (\% MCID) was based on the following threshold values: PCS-12, 8.8 points; MCS-12, 9.3 points; and ODI, 5.3 points. Multivariate regression analysis conducted using the back pain-dominant group as a baseline for comparison, controlling for age, sex, body mass index, smoking status, (never, current, former), follow-up (months), preoperative diagnosis of depression, preoperative workers compensation received, number of levels decompressed, and number of levels fused.

${ }^{6}$ Indicates statistical significance $(P<.05)$.

patients, 33.4\%) levels, whereas 318 patients had combined decompression and fusion $(64.4 \%)$ with most fusion cases involving only a single level (227 patients, $46.0 \%$ ). There were no differences in demographic data or surgical characteristics between groups other than age.

In the primary analysis, for patients undergoing decompression only, patients in all groups improved after surgery with respect to PCS-12 and ODI measures for both the primary and secondary analyses $(P<.05)$. MCS-12 significantly improved for patients in the L group $(51.2$ [95\% CI 48.1, 54.3] to $55.6[95 \%$ CI 53.5, 57.6]; $P=.004)$ but did not significantly improve for patients in the $\mathrm{B}$ and $\mathrm{N}$ groups $(P=.381$ and $P=.407$, respectively). Both VAS back and VAS leg scores improved significantly for all 3 groups $(P<.05)$. For patients undergoing fusions, PCS-12, MCS-12, and ODI scores significantly improved for all groups after surgery $(P<.05)$. Similar to the decompression cohort, patients in all 3 groups significantly improved with respect to VAS back and VAS leg scores $(P<.001)$. Comparing between groups in the primary analysis, there were no significant differences with respect to PCS-12, MCS12 , or ODI measures at the preoperative, postoperative, or delta outcome measures $(P>.05$; Table 2$)$. 
Table 3. Patient-reported outcome measurements between visual analog score leg-back ratio (LBR) groups. ${ }^{a}$

\begin{tabular}{|c|c|c|c|}
\hline & $\begin{array}{c}\text { Nonleg Pain- } \\
\text { Dominant (NLPD) } \\
(\text { LBR } \leq \mathbf{1 . 0})\end{array}$ & $\begin{array}{c}\text { Leg Pain- } \\
\text { Dominant (LPD) } \\
(\text { LBR }>1.0)\end{array}$ & $\begin{array}{c}\text { Univariate } \\
\text { Analysis } \\
(P \text { value }) \\
\end{array}$ \\
\hline $\begin{array}{l}\text { Decompression } \\
\text { PCS-12 }\end{array}$ & $n=86$ & $n=90$ & \\
\hline Delta & $10.6(8.4,12.9)$ & $9.7(7.3,12.1)$ & .587 \\
\hline RR, \% & 14.5 & 13.3 & .551 \\
\hline$\%$ MCID & 53.5 & 48.9 & .432 \\
\hline \multicolumn{4}{|l|}{ MCS-12 } \\
\hline Delta & $0.4(-2.4,3.1)$ & $3.9(1.7,6.0)$ & $.046^{\mathrm{b}}$ \\
\hline RR, \% & 2.1 & 5.2 & $.035^{\mathrm{b}}$ \\
\hline$\%$ MCID & 22.1 & 25.6 & .653 \\
\hline \multicolumn{4}{|l|}{ ODI } \\
\hline Delta & $-23.4(-28.4,-18.4)$ & $-20.3(-25.7,-14.9)$ & .396 \\
\hline RR, \% & 50.0 & 23.9 & .124 \\
\hline$\%$ MCID & 68.6 & 71.1 & .447 \\
\hline \multicolumn{4}{|l|}{ VAS back } \\
\hline Delta & $-4.1(-5.4,-2.8)$ & $-1.8(-2.5,-1.1)$ & $.002^{\mathrm{b}}$ \\
\hline RR, \% & 42.6 & 29.1 & .169 \\
\hline$\%$ MCID & 67.4 & 44.4 & $.002^{\mathrm{b}}$ \\
\hline \multicolumn{4}{|l|}{ VAS leg } \\
\hline Delta & $-3.2(-4.1,-2.3)$ & $-4.2(-5.0,-3.5)$ & .069 \\
\hline RR, \% & 37.3 & 54.4 & .108 \\
\hline$\%$ MCID & 60.5 & 66.7 & .393 \\
\hline Fusion & $n=163$ & $n=155$ & \\
\hline \multicolumn{4}{|l|}{ PCS-12 } \\
\hline Delta & $9.8(8.0,11.5)$ & $9.5(7.8,11.3)$ & .851 \\
\hline RR, \% & 13.2 & 13.3 & .987 \\
\hline$\%$ MCID & 50.3 & 50.3 & .781 \\
\hline \multicolumn{4}{|l|}{ MCS-12 } \\
\hline Delta & $4.2(2.6,5.8)$ & $3.1(1.2,5.0)$ & .382 \\
\hline RR, \% & 6.2 & 3.2 & .199 \\
\hline$\%$ MCID & 28.2 & 26.5 & .550 \\
\hline \multicolumn{4}{|l|}{ ODI } \\
\hline Delta & $-21.2(-24.6,-17.8)$ & $-19.7(-23.0,-16.4)$ & .521 \\
\hline RR, \% & 35.3 & 39.9 & .711 \\
\hline$\%$ MCID & 73.0 & 71.0 & .691 \\
\hline \multicolumn{4}{|l|}{ VAS back } \\
\hline Delta & $-3.8(-4.3,-3.3)$ & $-2.5(-3.0,-2.0)$ & $<.001^{\mathrm{b}}$ \\
\hline RR, \% & 48.0 & 33.3 & .116 \\
\hline$\%$ MCID & 65.6 & 52.3 & $.022^{\mathrm{b}}$ \\
\hline \multicolumn{4}{|l|}{ VAS leg } \\
\hline Delta & $-2.6(-3.2,-2.0)$ & $-4.9(-5.5,-4.4)$ & $<.001^{\mathrm{b}}$ \\
\hline RR, \% & 43.3 & 65.3 & $<.001^{\mathrm{b}}$ \\
\hline$\%$ MCID & 49.1 & 72.9 & $<.001^{\mathrm{b}}$ \\
\hline
\end{tabular}

Abbreviations: MCID, minimum clinically important difference; MCS-12, mental component score of the short form-12 survey; ODI, Oswestry Disability Index; PCS-12, physical component score of the short form-12 survey; RR, recovery ratio; VAS, visual analog score.

${ }^{a}$ LBR groups outcomes compared with univariate analysis (paired samples $t$ test, one-way analysis of variance with Bonferroni post hoc analysis, or Pearson chisquare analysis) and multivariate regression. Recovery ratios were defined as (delta outcome score/[optimal outcome score - observed outcome score]), where the following optimal outcome scores were used: 100 (PCS-12 and MCS-12) or 0 Neck Disability Index. The percentage of patients reaching the MCID (\% MCID) was based on the following threshold values: PCS-12, 8.8 points; MCS-12, 9.3 points; and ODI, 5.3 points. Multivariate regression analysis conducted using the back pain-dominant group as a baseline for comparison, controlling for age, sex, body mass index, smoking status, (never, current, former), follow-up (months), preoperative diagnosis of depression, preoperative workers compensation received, number of levels decompressed, and number of levels fused.

${ }^{\mathrm{b}}$ Boldface type indicates statistical significance $(P<.05)$.

In addition, there were no differences between groups when assessing change in outcomes with RR or percent of patients achieving MCID (Table 2). Using multiple linear regression in the primary analysis, having neutral or leg pain-predominant symptoms was not a significant predictor of improved outcomes compared with the back paindominant group.

In the secondary analysis, patients in all groups improved with respect to PCS-12, MCS-12, and ODI scores after surgery $(P<.05)$ except for patients undergoing decompression only in the NLPD group who experienced only a small increase in MCS-12 scores postoperatively $(50.1$ [47.6, 52.6] to $50.6[48.2,53.1] ; P=.782)$. Patients undergoing decompression or fusion both improved significantly with regards to VAS back and VAS leg scores after surgery $(P<.001)$. Comparing between groups, there were no differences in terms of preoperative, postoperative, or delta scores or differences in RR or percent of patients achieving MCID $(P>.05)$, except for MCS-12 scores in patients undergoing decompression surgery (Table $3)$. The LPD group demonstrated higher postoperative MCS-12 scores (54.4 versus 50.6; $P=.019$ ), larger delta scores (3.9 versus $0.4 ; P=.046)$, and a higher RR $(5.2 \%$ versus $2.1 \% ; P=.035)$. Using multiple linear regression in the secondary analysis, having leg pain dominance was associated with increased improvement in MCS-12 scores ( $\beta 3.336$ [0.543, 6.129]; $P=.020)$.

\section{DISCUSSION}

Degenerative spondylolisthesis and lumbar spinal stenosis are prevalent conditions that can result in both back and leg pain. While leg pain is commonly attributed to nerve root compression, identifying specific pain generators for LBP remains elusive. Recent studies have suggested that LBP in these conditions can arise from nerve root irritation, facet joint disease, or the intervertebral disc. ${ }^{15}$ Because of this wide variation, the amount of back pain in patients with similar diagnoses is also highly variable. Current surgical management is effective for relieving leg pain but is controversial for the treatment of back pain. In addition, it is currently unclear to what degree back pain improves in patients undergoing surgery for neurologic symptoms. Therefore, the aim of this study was to determine whether patients with back-dominant symptoms improved to a similar degree as patients with neutral or leg-dominant symptoms after lumbar surgery.

In this study, all groups $(\mathrm{B}, \mathrm{N}$, or L; NLPD or LPD) showed a significant improvement from baseline to postoperative measurements with regards to PCS-12 and ODI scores. In the primary 
and secondary analyses, there were no significant differences between groups with regards to PCS-12 and ODI scores. In addition, patients in the L or LPD groups undergoing decompression surgery showed improvement in MCS-12 scores, whereas those in the B, N, or NLPD groups did not show improvement. In the secondary analysis, patients undergoing decompression surgery also had higher absolute postoperative MCS-12 scores, higher delta scores, and a higher RR. In addition, multivariate analysis found that LPD was associated with a greater improvement in MCS-12 scores. However, when considering patients undergoing lumbar fusion surgery, there were no significant differences between groups using either analysis. These results suggest that patients undergoing lumbar spine decompression surgery for radiculopathy or claudication and with leg pain-dominant symptoms may have a benefit with regards to improved MCS-12 scores, whereas patients undergoing lumbar spine fusion surgery had similar outcomes regardless of back or leg pain dominance.

Few studies have assessed the effect of whether back or leg pain-dominant symptoms affect outcomes after surgery. Similar to the findings in this study, Stienen et $\mathrm{al}^{1}$ retrospectively analyzed 325 patients with either lumbar disc herniation or lumbar spinal stenosis that underwent decompression surgery and found that patients with back paindominant symptoms improved to a similar degree as patients with leg pain-dominant symptoms at all postoperative timepoints. The authors also found that patients with back pain dominance were 6 years older, which is contrary to the findings in this study where these patients were approximately 4 years younger. In two separate studies, Kleinstück et $\mathrm{al}^{10}$ and Kleinstueck et $\mathrm{al}^{11}$ analyzed the influence of preoperative back pain on the outcome of decompression surgery for lumbar spinal stenosis and lumbar disc herniation. The authors found that having greater back pain than leg pain preoperatively was associated with worse outcomes after decompression surgery for either diagnosis. ${ }^{10,11}$

However, Sigmundsson et $\mathrm{al}^{9}$ retrospectively analyzed 9051 patients in the Swedish Spine Register with a diagnosis of lumbar spinal stenosis with or without spondylolisthesis and found that patients with dominant back pain symptoms had inferior patient-reported outcomes as well as worse pain and function. The authors showed that patients that were most often satisfied with surgery were those whose back pain was less than their leg pain and those that were treated with decompression with fusion, whereas patients that were the least satisfied with surgery were those with back pain equal to or worse than their leg pain and underwent only decompression surgery. ${ }^{9}$ However, further analysis showed that the actual benefit with fusion is small and clinically insignificant. In an as-treated analysis of the Spine Patient Outcome Research Trial study, patients with degenerative spondylolisthesis or lumbar spinal stenosis were stratified by the location of their predominant pain (leg versus back), and those with leg pain-dominant symptoms improved significantly more than patients with back pain-dominant symptoms. ${ }^{12}$ These results were the same for 1- and 2-year follow-up. The long-term results of the Maine Lumbar Spine Study after 8 to 10 years showed that the patient's predominant symptom at the time of surgery (either low back or leg pain) improved in 54\% of patients; however, the study did not directly compare differences in patients reporting back-dominant versus leg-dominant symptoms. ${ }^{8}$

One explanation for the variation in the literature is that patients often have difficulty differentiating LBP from buttock and leg pain. This may lead to an incorrect diagnosis with the possibility for improper treatment that could affect long-term patient outcomes. Wai et $\mathrm{al}^{21}$ conducted a prospective, blinded, test-retest cohort study to determine whether patients could accurately identify whether their lumbar spine pain was leg or back dominant. The authors found that up to $32 \%$ of patients provided a completely opposite response on the retest, showing significant variability in the prevalence of leg pain. ${ }^{21}$ In addition, no single question was able to identify all patients with leg-dominant pain.

The results of this study suggest that patients undergoing lumbar decompression surgery with leg pain-dominant symptoms may have improved MCS-12 scores postoperatively. Patients undergoing lumbar fusion surgery had similar outcomes regardless of whether their symptoms were back pain dominant or leg pain dominant. The underlying biological reasons for this are still unclear and may be related to the fact that a portion of back pain may be attributable to neural compression and inflammation. ${ }^{22}$ In spite of these findings, there are some limitations to the present study. Given that it is a retrospective study, there is the possibility of 
selection bias. The use of VAS to stratify the group introduces recall bias, as patients may overestimate or underestimate their pain preoperatively. In addition, this cohort included patients undergoing both decompression and fusion surgery for a mixed set of diagnoses (degenerative spondylolisthesis, lumbar spinal stenosis, and lumbar disc herniation). While many of the aforementioned studies chose to separate these patients, this study analyzes the combined cohort to determine improvement in patients undergoing lumbar surgery for all causes. Lastly, the average follow-up for this study was approximately 13 months. Longer follow-up is needed to determine whether back or leg painrelated outcome measures remain constant over time.

\section{CONCLUSION}

In this study, there was no difference found in PCS-12 or ODI scores in patients with leg paindominant, back pain-dominant, or neutral symptoms; however, patients undergoing lumbar decompression surgery experienced a slight advantage with improvement in MCS-12 scores after surgery, whereas those undergoing lumbar fusion surgery improved similarly across all measures regardless of whether their symptoms were back or leg pain dominant. Further evidence is needed to determine whether these findings remain true at longer followup time points.

\section{REFERENCES}

1. Stienen MN, Joswig H, Smoll NR, et al. Short- and long-term effects of smoking on pain and health-related quality of life after non-instrumented lumbar spine surgery. Clin Neurol Neurosurg. 2016;142:87-92. doi:10.1016/j.clineuro. 2016.01.024

2. Hoy D, Bain C, Williams G, et al. A systematic review of the global prevalence of low back pain. Arthritis Rheum. 2012;64(6):2028-2037. doi:10.1002/art.34347

3. Martin BI, Deyo RA, Mirza SK, et al. Expenditures and health status among adults with back and neck problems. JAMA. 2008;299(6):656-664. doi:10.1001/jama.299.6.656

4. Indahl A, Velund L, Reikeraas O. Good prognosis for low back pain when left untampered. A randomized clinical trial. Spine (Phila Pa 1976). 1995;20(4):473-477. doi:10.1097/ 00007632-199502001-00011

5. Rainville J, Nguyen R, Suri P. Effective conservative treatment for chronic low back pain. Semin Spine Surg. 2009;21(4):257-263. doi:10.1053/j.semss.2009.08.009

6. Simon D, Coyle M, Dagenais S, O’Neil J, Wai EK. Potential triaging of referrals for lumbar spinal surgery consultation: a comparison of referral accuracy from pain specialists, findings from advanced imaging and a 3-item questionnaire. Can J Surg. 2009;52(6):473-480.

7. Mayman D, Yen D. Maximizing use of a surgical clinic for referrals of patients having back problems. Can J Surg. 1999;42(2):117-119.

8. Atlas SJ, Keller RB, Wu YA, Deyo RA, Singer DE. Longterm outcomes of surgical and nonsurgical management of sciatica secondary to a lumbar disc herniation: 10 year results from the Maine Lumbar Spine Study. Spine (Phila Pa 1976). 2005;30(8):927-935.

9. Sigmundsson FG, Jönsson B, Strömqvist B. Preoperative pain pattern predicts surgical outcome more than type of surgery in patients with central spinal stenosis without concomitant spondylolisthesis: a register study of 9051 patients. Spine (Phila Pa 1976). 2014;39(3):E199-E210. doi:10.1097/ BRS.0000000000000101

10. Kleinstück FS, Grob D, Lattig F, et al. The influence of preoperative back pain on the outcome of lumbar decompression surgery. Spine (Phila Pa 1976). 2009;34(11):1198-1203. doi:10.1097/BRS.0b013e31819fcf35

11. Kleinstueck FS, Fekete T, Jeszenszky D, et al. The outcome of decompression surgery for lumbar herniated disc is influenced by the level of concomitant preoperative low back pain. Eur Spine J. 2011;20(7):1166-1173. doi:10.1007/s00586010-1670-9

12. Pearson A, Blood E, Lurie $\mathrm{J}$, et al. Predominant leg pain is associated with better surgical outcomes in degenerative spondylolisthesis and spinal stenosis: results from the Spine Patient Outcomes Research Trial (SPORT). Spine (Phila Pa 1976). 2011;36(3):219-229. doi:10.1097/BRS.0b013e3181d77c21

13. Sedighi M, Haghnegahdar A. Lumbar disk herniation surgery: outcome and predictors. Global Spine J. 2014;4(4):233244. doi:10.1055/s-0034-1390010

14. Yamashita K, Ohzono K, Hiroshima K. Five-year outcomes of surgical treatment for degenerative lumbar spinal stenosis: a prospective observational study of symptom severity at standard intervals after surgery. Spine (Phila Pa 1976). 2006;31(13):1484-1490. doi:10.1097/01.brs.0000219940.26390. 26

15. Katz JN, Stucki G, Lipson SJ, Fossel AH, Grobler LJ, Weinstein JN. Predictors of surgical outcome in degenerative lumbar spinal stenosis. Spine (Phila Pa 1976). 1999;24(21):2229 2233. doi:10.1097/00007632-199911010-00010

16. Radcliff KE, Albert T, Coric D, Dolman W. Do patients with dominant neck pain improve as much as patients with dominant arm pain after cervical spine surgery? Abstract presented at: 19th Annual Conference of the International Society for the Advancement of Spine Surgery; April 3, 2019; Anaheim, CA.

17. Passias PG, Hasan S, Radcliff K, et al. Arm pain versus neck pain: a novel ratio as a predictor of post-operative clinical outcomes in cervical radiculopathy patients. Int J Spine Surg. 2018;12(5):629-637. doi:10.14444/5078

18. Radcliff K, Davis RJ, Hisey MS, et al. Long-term evaluation of cervical disc arthroplasty with the Mobi-C ${ }^{(}$ cervical disc: a randomized, prospective, multicenter clinical trial with seven-year follow-up. Int J Spine Surg. 2017;11 (4):31. doi: $10.14444 / 4031$

19. Parker SL, Adogwa O, Paul AR, et al. Utility of minimum clinically important difference in assessing pain, disability, and health state after transforaminal lumbar interbody fusion for degenerative lumbar spondylolisthesis. $J$ 
Neurosurg Spine. 2011;14(5):598-604. doi:10.3171/2010.12. SPINE10472

20. Parker SL, Mendenhall SK, Shau D, et al. Determination of minimum clinically important difference in pain, disability, and quality of life after extension of fusion for adjacent-segment disease. J Neurosurg Spine. 2012;16(1):61-67. doi:10.3171/2011.8.SPINE1194

21. Wai EK, Howse K, Pollock JW, Dornan H, Vexler L, Dagenais S. The reliability of determining "leg dominant pain." Spine J. 2009;9(6):447-453. doi:10.1016/j.spinee.2008.11.009

22. Hall H, Alleyne J, Rampersaud Y. Managing back dominant pain. J Current Clinical Care. 2013;Educational Supplement:24-31.

Disclosures and COI: The authors, their immediate family, and any research foundation with which they are affiliated did not receive any financial payments or other benefits from any commercial entity related to the subject of this article. There are no relevant disclosures.

Corresponding Author: Dhruv K.C. Goyal, MD, Rothman Orthopaedic Institute, Department of Orthopaedic Surgery, 925 Chestnut Street, 5th Floor, Philadelphia, PA 19107. Phone: 800-3219999; Fax: 267-479-1321; Email: dhruvkcgoyal@ gmail.com.

Published 19 August 2021

This manuscript is generously published free of charge by ISASS, the International Society for the Advancement of Spine Surgery. Copyright (C) 2021 ISASS. To see more or order reprints or permissions, see http://ijssurgery.com. 